\title{
Phylogeography of the sea star Marthasterias glacialis (Asteroidea, Echinodermata): deep genetic divergence between mitochondrial lineages in the north-western mediterranean
}

\author{
R. Pérez-Portela · A. Villamor • V. Almada
}

Received: 4 November 2009/Accepted: 29 April 2010/Published online: 26 May 2010

(C) Springer-Verlag 2010

\begin{abstract}
We explore the phylogeography of the broadcast spawner Marthasterias glacialis along south Europe and Azores. Sequences of the cytochrome $c$ oxidase gene from 225 specimens, belonging to 10 localities, were analysed. We found 73 haplotypes grouped within two lineages (divergence 2.9\%). One lineage was AtlantoMediterranean, whereas another one was exclusively Mediterranean. Estimation of lineages split goes back to $830,000-580,000( \pm 120,000)$ years ago. This suggests that sea-level oscillations during the Pleistocene glaciations promoted gene flow interruption, lineage divergence between basins and cryptic speciation. Secondary contact between populations allowed a recolonization of the Mediterranean by the Atlantic lineage. When animals of the Atlanto-Mediterranean lineage were considered separately, $F_{\text {st }}$ index and AMOVA did not show significant differences between populations along either the Iberian Peninsula or basins. Isolation by distance between populations was not detected, and only populations of Plymouth and Azores showed significant differences to all the others.
\end{abstract}

Communicated by S. Uthicke.

R. Pérez-Portela $(\bowtie) \cdot$ V. Almada

Eco-Ethology Research Unit,

Instituto Superior de Psicologia Aplicada (ISPA),

Rua Jardim do Tabaco, 34, 1149-041 Lisbon, Portugal

e-mail: Perezportela@gmail.com; rocio_perez@ub.edu

R. Pérez-Portela

Department of Animal Biology (Invertebrates),

Faculty of Biology, University of Barcelona, 645,

Diagonal Avenue, 08028 Barcelona, Spain

A. Villamor

Center for Advanced Studies of Blanes (CEAB, CSIC),

Accés a la Cala St. Francesc 14, 17300 Blanes, Girona, Spain
The remoteness of Azores islands might explain the structure of this population. Haphazard arrival of larvae and local extinctions rather than contemporary restricted gene flow might be responsible for the distinctive population structure of Plymouth.

\section{Introduction}

It is currently well known that barriers to gene flow exist in the ocean realm generating different levels of population differentiation in marine species (Hellberg 1996; Lessios et al. 2001; Hedgecock et al. 2007). Gene flow between populations, promoted by migration and dispersion of both larvae and adults, does not only preclude local adaptation (Barton and Hewitt 1985) but also introduces new polymorphisms in the populations on which selection can potentially act. Therefore, dispersal distances may not only influence geographical range and genetic structure of the species, but also play an important role in population differentiation and speciation processes with profound consequences for the species' phylogeography (Solé-Cava and Thorpe 1991). Differences in species dispersal are primarily determined by the ontogeny of the organisms and are partially correlated with the time that larvae spend in the plankton. However, it has been demonstrated that even in species with apparently high dispersal capability, relatively strong population structure may occur (Launey et al. 2002; Zane et al. 2000). Potential long-distance movements may also be hindered by the existence of other physical and historical factors acting on population's connectivity. Observed patterns of genetic diversity distribution reflect the historical and contemporary interplay among ecological, demographic, behaviour, genetic, oceanographic, tectonic and climatic processes (Palumbi 1995; Benzie 1999). 
Marine environments have been influenced by recurrent events of sea level fluctuations and climate changes. Cold glacial periods followed by warm interglacial periods during the Quaternary caused interruptions and reconnections between water masses with important implications for the species distribution, evolutionary history and speciation processes (Wares and Cunningham 2001). For instance, the Pleistocene ice ages (after $2.4 \mathrm{my}$ ) subdivided and promoted population differentiation of a number of Atlantic and Pacific coastal species by periodically closing their migratory routes (Cunningham and Collins 1998; Lessios et al. 2001, 2003).

Hydrological factors may also be one of the strongest forces shaping gene flow in the marine realm. Water current regimes at several scales, from the largest general circulation to the smallest local eddies, are capable to reduce dramatically the connection between nearby areas acting like physical barriers or, on the contrary, enhancing flow between distant areas. Thereby, marine circulation regimes may profoundly influence the distributional patterns of the oceans (Benzie 1999; Lessios et al. 2001; Le Gac et al. 2004; Addison and Hart 2004).

Marine areas separated by straits are an interesting focus of study since these specific zones, dominated by sudden changes on depth and strong current regimes, have been repeatedly subjected to disconnections and reconnections during the glaciation events (Wares and Cunningham 2001; Maggs et al. 2008). A number of studies on the phylogeography of marine invertebrates have been carried out at both sides of the Bass Strait that separates eastern from southern Australia (Waters and Roy 2003), the Bass Strait between South America and the Antarctic Peninsula (Hunter and Halanych 2008) and the Gibraltar Strait (Zulliger et al. 2009), which is the only connection between the Atlantic Ocean and the Mediterranean Sea and measures less than 11 miles wide. In the case of the AtlantoMediterranean transition, the Almeria-Oran Front (AOF) located inside the Mediterranean has been defined as the main boundary between Atlantic and Mediterranean surface waters, but the transition at the biological level still remains controversial (Borsa et al. 1997; Cimmaruta et al. 2005; Patarnello et al. 2007) and marine species display different patterns of genetic structure at both sides of this particular area (e.g. Quesada et al. 1995; Launey et al. 2002; Rios et al. 2002; Bargelloni et al. 2003). Population genetic analyses have been applied to a scarce number of echinoderm species along the Atlantic-Mediterranean area, but the available data demonstrated different levels of gene flow between basins depending not only on the species' life history but also on the genetic markers used. For instance, the high dispersal sea urchin Paracentrotus lividus showed a sharp break between populations at both sides of the $\mathrm{AOF}$, as well as a higher genetic diversity in Mediterranean populations (Calderon et al. 2008). However, for the broadcast spawner Astropecten aranciacus, populations seemed to be isolated by distance but genetic divergences were not related with a gene flow interruption between basins (Zulliger et al. 2009).

Because we are far from understanding how the AOF distinctively affects gene flow of marine species, more phylogeographic data of Atlanto-Mediterranean species, with different life histories and dispersive capabilities, are needed in order to get a more comprehensive picture of the importance of this particular transition in shaping the distribution of genetic diversity at both basins.

Marthasterias glacialis (order Forcipulata, Asteriidae) is widely distributed in Europe, from Finnmark (the northernmost county of Norway) to the Mediterranean Sea (Harmelin et al. 1980; Nichols and Barker 1984; Savy 1987), being a common and emblematic species at both sides of the Gibraltar Strait, predator of bivalves and other echinoderms (Barker and Nichols 1983; Frid 1992; Guidetti 2004). Despite its abundance in the North Atlantic sublittoral habitats, it is not, in general, abundant along the Mediterranean littoral, rarely reaching densities up to 2 ind $/ 50 \mathrm{~m}^{2}$ (Savy 1987). According to Mortensen (1927), the British populations of the species have one single breeding season whereas, Mediterranean populations breed twice per year. $M$. glacialis is a broadcast spawner sea star, with long dispersal capability due to a planktotrophic larva, which remains in the water column for more than 3 months, passing through several larval stages. When adhesive structures appear, the larva attaches to the substrate and the metamorphosis commences (Barker and Nichols 1983).

The cytochrome $c$ oxidase I (COI) gene has been widely used in marine invertebrates offering a good level of genetic variation suitable for analyses at different scales (Tarjuelo et al. 2001; Pérez-Portela and Turon 2008), from phylogenetic to population genetic analyses (Avise 2000), and being able to retain the signature of both past and present demographic events that affected the populations and species (Duran et al. 2004). Moreover, this gene has successfully been used in echinoderm species making our results comparable with those previously observed for other species (see e.g. Baric and Sturmbauer 1999; Lessios et al. 2003; Uthicke and Benzie 2003; Muths et al. 2009).

The main objectives of the present study are the following: (1) to explore the level of genetic structure of Marthasterias glacialis along the Southwest European coast, (2) to analyse the distribution of the genetic diversity in order to determine the effects of contemporary events versus historical demography and (3) to investigate the possible existence of barriers to gene flow between the Atlantic and Mediterranean basins for a species with high dispersal larva. 


\section{Materials and methods}

\section{Sampling}

Samples of Marthasterias glacialis were collected between 2006 and 2009 from 10 different localities (Fig. 1, Table 1); nine of them from the Northeast Atlantic coast (Plymouth, Mutriku, Santander, Ares, Cascais, San Pedro, São Viçente, Sagres and São Miguel) and one from the Northwest Mediterranean coast (Costa Brava), covering a significant range of the species' distribution in Europe. Specimens were sampled either by SCUBA diving (depth between 5 and $25 \mathrm{~m}$ ) or were directly handed from rocky shore intertidal. Between 13 and 31 sea stars were collected per population, with the exception of San Pedro where only 3 individuals could be sampled due to the low population density of the species in this particular locality. Regarding the Costa Brava samples, specimens of $M$. glacialis were collected from 10 different localities (separated between 3 and $10 \mathrm{~km}$ ) since densities of the species are so low that no more than nine individuals could be collected per location (see Table 2).

Tube feet of each individual were removed with forceps, fixed in absolute ethanol and preserved at $-20^{\circ} \mathrm{C}$ until processing. Animals were immediately released after tissue collection.

\section{DNA analysis}

Total DNA was extracted using a REDExtract-N-Amp kit (Sigma-Aldrich, www.sigma.com) from one or two tube feet. A fragment of the COI gene was amplified and sequenced. Universal primers described in Folmer et al. (1994) were initially used for the amplification of a fragment of the COI. In order to increase the quality of the sequencing reaction, from the first sequences available, we designed specific primers with the software PRIMER vs. 3.0 (http://www.fokker. wi.mit.edu/primer3/input.htm) as follows: MgCOI_F 5' TC TCATATTTGGAGCTTGAG $3^{\prime}$ and MgCOI_R $5^{\prime}$ TAGG TGTTGAAAGAGAATGG $3^{\prime}$. PCR amplification reactions were performed in a $20 \mu \mathrm{l}$ total-reaction volume with $10 \mu \mathrm{l}$ of REDExtract-N-ampl PCR reaction mix (Sigma-Aldrich), $0.8 \mu \mathrm{l}$ of each primer $(10 \mu \mathrm{M}), 4.4 \mu \mathrm{l}$ of ultrapure water (Sigma-Aldrich) and $4 \mu \mathrm{l}$ of template DNA. A single soak at $94^{\circ} \mathrm{C}$ for 7 min was followed by 35 cycles (denaturation at $94^{\circ} \mathrm{C}$ for $30 \mathrm{~s}$, annealing at $48^{\circ}$ for $30 \mathrm{~s}$ and extension at $72^{\circ} \mathrm{C}$ for $35 \mathrm{~s}$ ) and a final extension at $72^{\circ} \mathrm{C}$ for $7 \mathrm{~min}$ on a thermal cycler (BioRad Mycycler, www.biorad.com). The same primers were used for the sequencing reaction, and the PCR products were purified and sequenced in STABVIDA (http://www.stabvida.net/).

All the sequences were edited and aligned using CodonCode vs. 2.0 software (http://www.codoncode.com/),

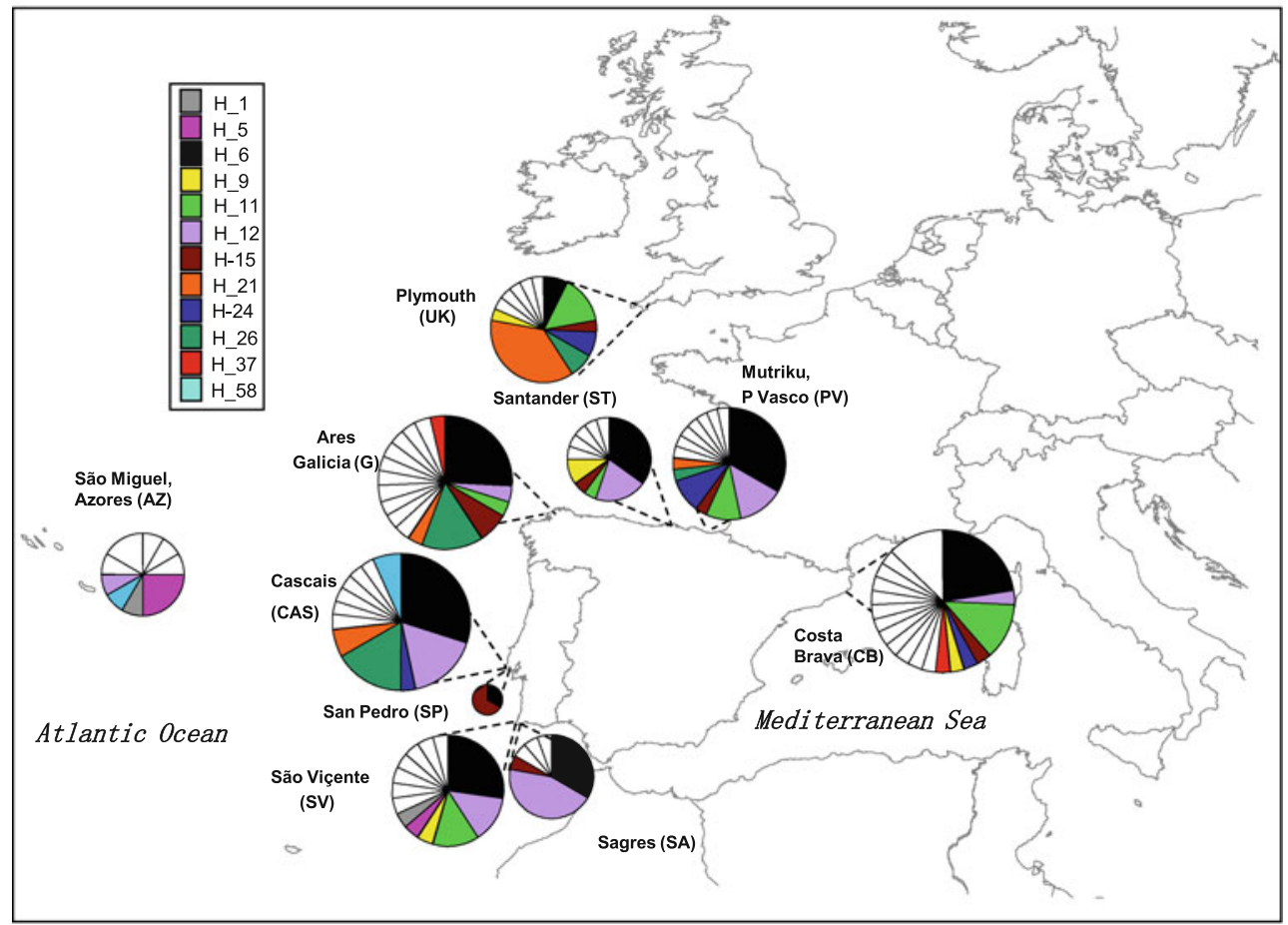

Fig. 1 Map of the sampling scheme for Marthasterias glacialis. Pie charts represent haplotype frequencies for each population, and their size is proportional to sample size. Private haplotypes for each population are represented in white colour 
Table 1 Diversity measures for populations of Marthasterias glacialis from COI

\begin{tabular}{|c|c|c|c|c|c|c|c|c|}
\hline Population & Code & Coordinates & $n$ & $N h$ & $N p$ & $\% N p$ & $H d$ & $\pi$ \\
\hline Plymouth, UK & UK & $50^{\circ} 18^{\prime} 51.54^{\prime \prime} \mathrm{N} 4^{\circ} 9^{\prime} 15.71^{\prime \prime} \mathrm{W}$ & 28 & 12 & 5 & 41.6 & $0.854( \pm 0.055)$ & $0.00829( \pm 0.00070)$ \\
\hline Mutriku, Basque country & PV & $43^{\circ} 19^{\prime} 51.19^{\prime \prime} \mathrm{N} 2^{\circ} 21^{\prime} 45^{\prime \prime} \mathrm{W}$ & 30 & 14 & 7 & 50 & $0.869( \pm 0.049)$ & $0.00494( \pm 0.00079)$ \\
\hline Bahía, Santander & ST & $43^{\circ} 28^{\prime} 41.23^{\prime \prime} \mathrm{N} 3^{\circ} 4934^{\prime \prime} \mathrm{W}$ & 20 & 10 & 5 & 50 & $0.853( \pm 0.063)$ & $0.00642( \pm 0.00119)$ \\
\hline Ares, Galicia & G & $43^{\circ} 25^{\prime} 2.34^{\prime \prime} \mathrm{N} 8^{\circ} 14^{\prime} 29.51^{\prime \prime} \mathrm{W}$ & 28 & 17 & 10 & 58.8 & $0.923( \pm 0.037)$ & $0.00794( \pm 0.00073)$ \\
\hline Cabo Raso, Cascais & CAS & $38^{\circ} 41^{\prime} 29.93^{\prime \prime} \mathrm{N} 9^{\circ} 25^{\prime} 49.13^{\prime \prime} \mathrm{W}$ & 31 & 12 & 6 & 50 & $0.873( \pm 0.039)$ & $0.00715( \pm 0.00082)$ \\
\hline São Viçente & SV & $37^{\circ} 1^{\prime} 17.37^{\prime \prime} \mathrm{N} 8^{\circ} 59^{\prime} 37.82^{\prime \prime} \mathrm{W}$ & 22 & 13 & 7 & 53.8 & $0.909( \pm 0.045)$ & $0.00593( \pm 0.00132)$ \\
\hline Sagres & SA & $36^{\circ} 59^{\prime} 53.85^{\prime \prime} \mathrm{N} 8^{\circ} 56^{\prime} 54.92^{\prime \prime} \mathrm{W}$ & 19 & 7 & 3 & 42.8 & $0.749( \pm 0.075)$ & $0.00342( \pm 0.00079)$ \\
\hline São Miguel, Azores & $\mathrm{AZ}$ & $37^{\circ} 43^{\prime} 44.77^{\prime \prime} \mathrm{N} 25^{\circ} 31^{\prime} 38.13^{\prime \prime} \mathrm{W}$ & 13 & 9 & 5 & 55.5 & $0.910( \pm 0.068)$ & $0.00754( \pm 0.00137)$ \\
\hline San Pedro de Estoril & SP & $38^{\circ} 41^{\prime} 11.23^{\prime \prime} \mathrm{N} 9^{\circ} 21^{\prime} 20.71^{\prime \prime} \mathrm{W}$ & 3 & 2 & 0 & & $0.667( \pm 0.314)$ & $0.00639( \pm 0.00301)$ \\
\hline Atlantic basin & & & 194 & 61 & 50 & 81.9 & $0.904( \pm 0.014)$ & $0.00703( \pm 0.00015)$ \\
\hline \multicolumn{9}{|l|}{ Mediterranean basin } \\
\hline Costa Brava & $\mathrm{CB}$ & & 31 & 19 & 12 & 63.17 & $0.929( \pm 0.031)$ & $0.01359( \pm 0.00184)$ \\
\hline Only Lineage I & & & 25 & 16 & 9 & 56.25 & $0.910( \pm 0.002)$ & $0.00708( \pm 0.00102)$ \\
\hline Total & & & 225 & 73 & 61 & 83.5 & $0.911( \pm 0.013)$ & $0.00811( \pm 0.00053)$ \\
\hline
\end{tabular}

Population, population code, coordinates of sampling location, number of individuals ( $n$ ), number of haplotypes (Nh), number of private haplotypes $(N p)$, percentage of private haplotypes $(\% N p)$, haplotype diversity $(H d)$ and nucleotide diversity $(\pi)$ are shown. Numbers in brackets are standard deviations

Table 2 Localities from Costa Brava, positions, total number of individuals $(n)$, number of individuals belonging to Lineage I and number of individuals belonging to Lineage II

\begin{tabular}{lllll}
\hline Locality & Position & $n$ & Lineage I & Lineage II \\
\hline Blanes & $41^{\circ} 40^{\prime} 25.62^{\prime \prime} \mathrm{N} 2^{\circ} 48^{\prime} 10.68^{\prime \prime} \mathrm{E}$ & 9 & 7 & 2 \\
Cala Sant Francesc & $41^{\circ} 40^{\prime} 42.73^{\prime \prime} \mathrm{N} 2^{\circ} 48^{\prime} 25.94^{\prime \prime} \mathrm{E}$ & 1 & 1 & 0 \\
Pared Bisbe & $42^{\circ} 14^{\prime} 19.26^{\prime \prime} \mathrm{N} 3^{\circ} 15^{\prime} 21.44^{\prime \prime} \mathrm{E}$ & 7 & 6 & 1 \\
Els Caials & $42^{\circ} 17^{\prime} 00.80^{\prime \prime} \mathrm{N} 3^{\circ} 17^{\prime} 15.44^{\prime \prime} \mathrm{E}$ & 3 & 3 & 0 \\
ŚArnella & $42^{\circ} 20^{\prime} 11.73^{\prime \prime} \mathrm{N} 3^{\circ} 12^{\prime} 13.28^{\prime \prime} \mathrm{E}$ & 3 & 2 & 1 \\
Cap Norfeu & $42^{\circ} 14^{\prime} 37.54^{\prime \prime} \mathrm{N} 3^{\circ} 15^{\prime} 57.40^{\prime \prime} \mathrm{E}$ & 2 & 2 & 0 \\
El Gat & $42^{\circ} 14^{\prime} 13.54^{\prime \prime} \mathrm{N} 3^{\circ} 15^{\prime} 50.59^{\prime \prime} \mathrm{E}$ & 2 & 0 & 2 \\
Montgrí & $42^{\circ} 3^{\prime} 40.33^{\prime \prime} \mathrm{N} 3^{\circ} 13^{\prime} 0.83^{\prime \prime} \mathrm{E}$ & 2 & 2 & 0 \\
Rostella & $42^{\circ} 14^{\prime} 39.01^{\prime \prime} \mathrm{N} 3^{\circ} 15^{\prime} 32.25^{\prime \prime} \mathrm{E}$ & 1 & 1 & 0 \\
Sant Feliú Guixols & $41^{\circ} 46^{\prime} 43.43^{\prime \prime} \mathrm{N} 3^{\circ} 02^{\prime} 44.37^{\prime \prime} \mathrm{E}$ & 1 & 1 & 0 \\
\hline
\end{tabular}

and results from the alignment were verified by eye. Sequences of the haplotypes found in this study have been deposited in GenBank (accession numbers from HM107700 to HM107772) (http://www.genbank.com).

Phylogeography and phylogeny

The complete dataset was used to construct an unrooted network, under the null hypothesis of no genetic differentiation among populations. We used the Network vs. 4.5.1.0 program (http://www.fluxus-engineering.com/ sharenet.htm), which assumes the median-joining network method in the absence of recombination (Bandelt et al. 1999). This method begins by combining the minimum spanning trees within a single network. With a parsimony criterion, median vectors ("mv", which represent missing intermediates haplotypes) are added to the network. The loops observed in the networks were solved using the criteria derived from coalescent theory (Templeton et al. 1987; Templeton and Sing 1993).

For phylogenetic analysis of the haplotypes obtained, we included a sequence of Urasterias licki from GenBank (Acc number DQ077934.1) as an outgroup. The best-fit model of nucleotide substitution for the data was selected by statistical comparison of 56 different models of evolution with Modeltest vs. 3.0 (Posada and Crandall 1998) using the Akaike Information Criterion (AIC). Values of the evolution model selected were then fed into MrBayes software (Huelsenbeck and Ronquist 2001), and the haplotype tree under the Bayesian Inference (BI) criterion was estimated after 1 million generations with a sample frequency of 100 (10,000 final trees). After verifying that stationarity had been reached, the first 1,000 trees were discarded and an independent majority-rule consensus tree was generated from the remaining trees (9,000 trees). 
Genetic divergence within and between lineages of M. glacialis were calculated by a Kimura two parameters distance in MEGA vs. 3.0, and divergence times were inferred applying a molecular clock.

Population genetic analyses

Numbers of haplotypes $(N h)$, haplotype diversity $(H d)$ and nucleotide diversity $(\pi)$ values were computed with DnaSP vs. 4.10 .3 (Rozas et al. 2003). Samples from San Pedro were omitted from population genetics analyses because of the low sample number. The existence of different population groupings was tested with the software SAMOVA vs. 1.0 (Dupanloup et al. 2002) (http://www.web.unife. it/progetti/genetica/Isabelle/samova.html). An analysis of molecular variance (AMOVA) was performed to examine population structure, and its significance was tested running 16,000 permutations in Arlequin vs. 3.1 (Excoffier et al. 2005). Populations were grouped within Atlantic and Mediterranean basins following our prior expectation of a genetic division caused by the "basin boundary". For further analyses of population genetic structure, pairwise genetic distances $\left(F_{s t}\right)$ between populations was assessed by performing 10,000 permutations with the same software. A multidimensional scaling performed on Primer vs. 6 (Clarke and Warwick 2001) was used to graphically visualize these Fst results.

Finally, in order to detect the effect of isolation by geographical distance, we compared the correlation of genetic distances $\left(F_{s t} / 1-F_{s t}\right)$ with log-transformed geographical distances. Isolation by distance was tested for all pairs of populations with the Mantel test procedure as proposed by Rousset (1997), and 10,000 permutations were executed in Arlequin vs. 3.1.

Demographic analysis

The history of effective population size was tested by the mismatch distribution as the distribution of pairwise differences among all haplotypes in a sample following the models of Rogers and Harpending (1992) and Rogers (1995) in Arlequin vs. 3.1. The mismatch distribution method is based on the assumption that stable population sizes present a multimodal distribution of growths and declines, leaving a characteristic signature in the DNA sequences, so recent population growth is expected to generate a unimodal distribution of pairwise differences between sequences of a given sample. We assessed the fit of mismatch distributions to the theoretical distribution in an expansion scenario by simulation. The sum of squared deviations between observed and expected mismatch distributions was used as a test statistic, and its $P$-value represents the probability of obtaining a simulated sum of squared deviations larger or equal to the observed one.

Since the mismatch distribution approach has been considered very conservative in inferring population expansion events (Ramos-Onsins and Rozas 2002), the history of effective population size was also assessed by means of other statistics such as Tajima's $D$ test (Tajima 1989), Fu's $F_{\mathrm{s}}$ test (Fu 1997) and $R^{2}$ test (Ramos-Onsins and Rozas 2002) using DnaSP vs. 4.20 (Rozas and Rozas 1999). These tests have been used to detect changes in population size. Analyses were performed for all populations as well as for the populations pooled into two regions, the Atlantic and Mediterranean.

In order to estimate the approximate time of demographic expansion in generations $(t)$ of Atlantic and Mediterranean populations of Marthasterias glacialis from coalescence methods, we used the equation $T=2 u t$ (Rogers and Harpending 1992), where $T$ is the date of the growth or decline measured in units of mutational time and $u$ is the mutation rate per sequence and per generation. The value of $u$ was calculated from $u=2 \mu k$, where $\mu$ is the mutation rate per nucleotide and $k$ is the number of nucleotides of the analysed fragment. The general mutation rates applied for echinoid COI have been reported to range from 1.6 to $3.5 \%$ per million years (Lessios et al. 1999; McCartney et al. 2000), but estimates in Asterinidae sea star species fixed this value around $5 \%$ per million years (Hart et al. 1997). We used both mutation rates to calculate demographic and divergence events in order to represent the estimated range in all the Echinodermata.

\section{Results}

\section{Genetic diversity}

We obtained 626 bp of the mitochondrial gene COI from 225 individuals of Marthasterias glacialis from nine Atlantic localities and one Mediterranean locality (see Fig. 1). From the 75 polymorphic sites (12\%), only eight of them corresponded to non-synonymous substitutions. Four of the non-synonymous substitutions were only found in São Vicente population (SV). A total of 73 haplotypes were obtained from all the sequences, and 60 of them were private haplotypes $(82 \%)$. The number of haplotypes per location ranged between two in San Pedro (where only three specimens were sequenced) and 19 in the Mediterranean area. Haplotype diversity $(H d)$ and nucleotide diversity $(\pi)$ assessed for the whole geographical range were $0.911( \pm 0.013 \mathrm{SD})$ and $0.0081( \pm 0.000 \mathrm{SD})$, respectively (Table 1 ). Both, $H d$ and $\pi$ were much higher for the Mediterranean area, when Lineage I and II were 
pooled together (0.929 and 0.014 , respectively), than Atlantic ones (average for Atlantic populations $H d=0$. 845, $\pi=0.006$ ). Moreover, the Mediterranean basin showed the highest number of haplotypes and level of private haplotypes. We observed that H_6 was the most common haplotype and was the only one represented within most of the main populations (see Table 6). The next most frequent haplotype, H_12, was represented all along the Iberian Peninsula coast and Azores, but it did not appear in the UK population.

Phylogeny and phylogeography

The network obtained for COI presented six loops that could be unambiguously resolved (Fig. 2a). The results demonstrated the existence of two sharp divergent lineages within the Mediterranean basin lacking intermediate haplotypes that connect both networks. Distance between both lineages was 13 mutations steps.

Whereas Lineage I had an Atlanto-Mediterranean distribution and was represented in every population, Lineage II was represented by only three Mediterranean haplotypes (six individuals). The BI tree reconstructed from the haplotypes showed a shallow phylogeny where relationships near tips were not strongly supported and largely unresolved. Separation between lineages, of being mutually monophyletic groups, was supported by 0.72 of posterior probability (Fig. 2b). Divergence of lineages was also consistent with a bimodal mismatch distribution observed into the Mediterranean basin (see full explanation in Demographic events). According with the network results, H_6 and H_12 may be the ancestral haplotypes within Lineage I due to their high frequency, wide geographical distribution and central position within the network.

Genetic distance between lineages was estimated as $2.9 \%$ (Kimura 2 parameters), whereas intra-lineage distances were much lower reaching values of 0.92 and $0.32 \%$ for Lineage I and II, respectively. Applying a molecular clock and assuming constant rates of mutation, estimations of divergence between Lineages I and II of Marthasterias glacialis happened around 580,000 and 830,000 years ago (confidence interval of $\pm 120,000$ years), according to a molecular clock of 5\% -My calibrated for COI in Asterinidae or $3.5 \%$-My for sea urchins, respectively.
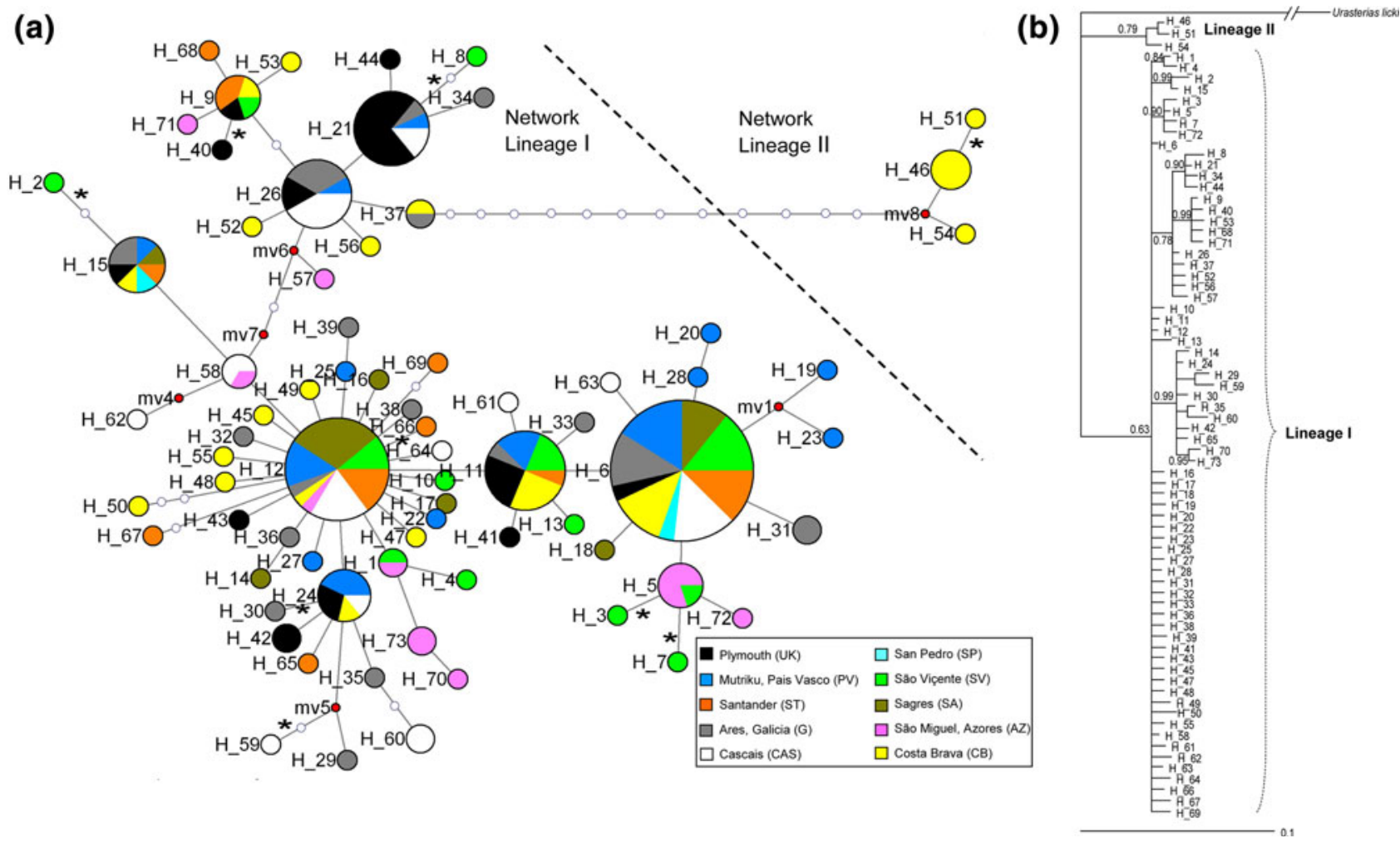

Fig. 2 a Median-joining haplotype network for Marthasterias glacialis from COI. Area of the circles is proportional to the number of individuals found for each haplotype. Partitions inside the circles represent the proportion of each population within each haplotype. Red dots ("mv") represent missing, probably unsampled haplotypes or extinct sequences. Lines between circles represent one mutational step and * non-synonymous substitutions; b Bayesian Inference phylogenetic tree from the haplotypes rooting the tree with a sequences of the species Urasterias licki; values of posterior probabilities are indicated when $>0.5$ 
Table 3 Analysis of the molecular variance (AMOVA) for the COI from populations of Marthasterias glacialis

\begin{tabular}{|c|c|c|c|c|c|c|}
\hline Source of variation & d.f. & Sum of squares & Variance components & $\%$ Variation & $P$ value & Fixation index \\
\hline \multicolumn{7}{|l|}{ AMOVA between basins } \\
\hline Among groups & 1 & 0.754 & -0.00631 & -1.39 & 0.443 & Fct: -0.0139 \\
\hline Among populations within groups & 7 & 6.648 & 0.02159 & $4.75^{*}$ & 0.000 & Fsc: 0.04688 \\
\hline Within populations & 213 & 93.476 & 0.43885 & $96.64^{*}$ & 0.000 & Fst: 0.03364 \\
\hline \multicolumn{7}{|l|}{ AMOVA without grouping } \\
\hline Among populations & 8 & 7.402 & 0.01987 & $4.33 *$ & 0.000 & Fst: 0.04331 \\
\hline Within populations & 213 & 93.47 & 0.43888 & 95.67 & & \\
\hline Total & 221 & 100.878 & 0.45872 & & & \\
\hline
\end{tabular}

Analyses are presented pooling population from Mediterranean and Atlantic basins and for the whole area without grouping

Table 4 Population pairwise genetic differentiation $\left(F_{\mathrm{st}}\right)$ between sampled populations of Marthasterias glacialis

\begin{tabular}{|c|c|c|c|c|c|c|c|c|}
\hline & UK & PV & ST & $\mathrm{G}$ & CAS & SV & SA & $\mathrm{AZ}$ \\
\hline PV & $0.23771 * *$ & & & & & & & \\
\hline ST & $0.15645 * *$ & -0.00152 & & & & & & \\
\hline $\mathrm{G}$ & $0.06652 *$ & 0.03158 & -0.00103 & & & & & \\
\hline CAS & $0.09201 * *$ & 0.02177 & -0.00594 & -0.02378 & & & & \\
\hline SV & $0.22309 * *$ & 0.00561 & 0.00267 & 0.043591 & 0.04142 & & & \\
\hline SA & $0.2754 * *$ & -0.00683 & 0.00200 & $0.05915^{* *}$ & 0.04722 & 0.01882 & & \\
\hline $\mathrm{AZ}$ & $0.21992 * *$ & $0.13125^{* *}$ & $0.10036^{*}$ & $0.09945^{*}$ & $0.09904 *$ & $0.06028 *$ & $0.16250 * *$ & \\
\hline CB (Lineage I) & $0.12208^{* *}$ & 0.01085 & -0.02987 & -0.01516 & -0.01451 & 0.01110 & $0.02307 *$ & $0.10283^{*}$ \\
\hline CB (lineage I and II) & $0.11238 * *$ & $0.10244 * *$ & $0.05153^{*}$ & $0.04845^{*}$ & $0.05740 *$ & $0.08751^{*}$ & $0.10016^{*}$ & $0.07736^{* *}$ \\
\hline
\end{tabular}

* Signification at $P<0.05$ and ** highly significant when $P<0.01$

\section{Population structure}

The SAMOVA for $\mathrm{K}=2$ clustered the Mediterranean (CB) and the Atlantic Iberian Peninsula within a group and the Azores and UK population in other two group.

The AMOVA grouping populations in the Atlantic and Mediterranean groups revealed that most of the genetic diversity was due to variability within populations $(96.6 \%$, $P=0.000)$ and between populations within basins $(4.75 \%$, $P=0.000$ ), but no significant differences in genetic structure were detected between Atlantic and Mediterranean basins ( $P=0.443$; Table 3$)$.

Further analyses based on pairwise comparisons $(F \mathrm{st})$ showed significant differences between UK (Plymouth) and all the other populations and between AZ (Azores) and all the populations except SV (São Vicente; Table 4). Also, CB (Costa Brava) revealed significant differences with most of the populations when both lineages, Lineage I and II, were included into the analyses. Due to the high genetic divergence between Lineage I and II and in order to avoid grouping together two different genetic pools with different demographic histories, $F$ st calculations were also performed for $\mathrm{CB}$ including only Lineage I. When the $\mathrm{CB}$ was analysed excluding individuals belonging to Lineage II, non-significant differences with Atlantic populations of the
Iberian Peninsula were detected but differences with AZ and UK populations remained significant, reflecting the lack of strong genetic structure within the Iberian Peninsula.

The MDS showed populations around the Iberian Peninsula grouped together and the AZ and UK populations separated from the rest (Fig. 3). Despite these differences in genetic structure between populations, they did not fit to the isolation by distance model; the Mantel test did not show a significant correlation between genetic differentiation and geographical distance $(r=0.046 ; P=0.123)$. This suggests that the differentiation is not directly related to geographical distance and that other hydrological or historical demographic events might have played an important role in cutting off the connectivity between AZ, UK and other areas.

Demographic events

The parameters of the mismatch distribution for each population independently, for Atlantic basin populations and for all populations, pooled together were not significantly different from a sudden expansion model (Fig. 4). The Costa Brava displayed a distinctive bimodal pattern with distant peaks, coherent with the presence of two 


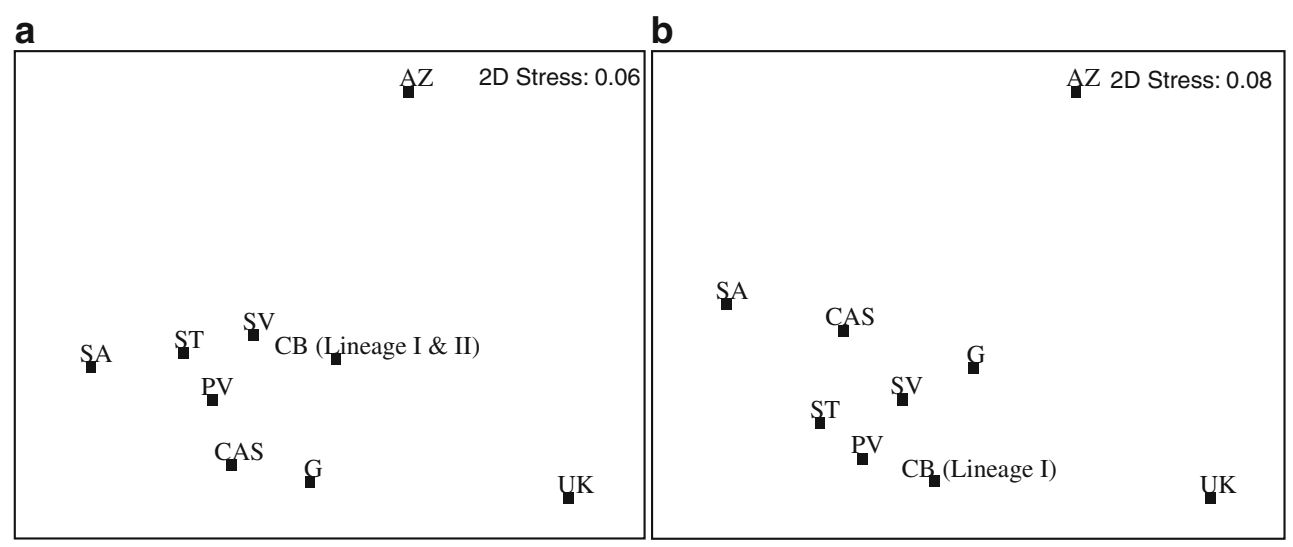

Fig. 3 Multidimensional scaling (MDS) for the COI of Marthasterias glacialis from the $F_{\text {st }}$ values. a from $F_{\text {st }}$ including Lineage I and II and $\mathbf{b}$ from $F_{\text {st }}$ including only Lineage I

Fig. 4 Mismatch distribution. Graphs represent the mismatch distribution for Mediterranean basin including and excluding Lineage II, Atlantic basin and the whole dataset
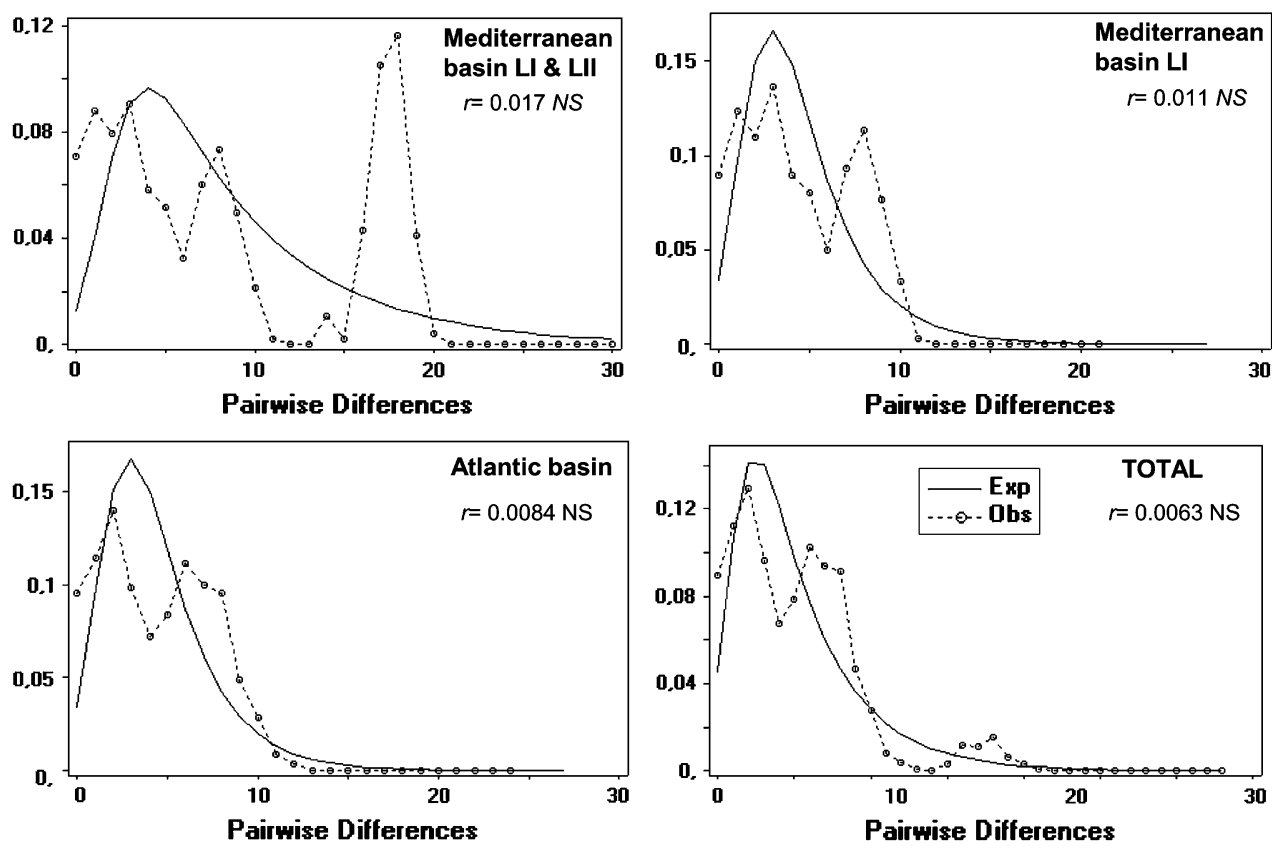

different lineages or genetic pools. This fact justified performing analyses separately (including and excluding Lineage II), and in both cases, we could not reject the hypothesis of sudden expansion in the Mediterranean.

The three neutrality tests statistics, Tajima's $D$, Fu's $F_{\mathrm{s}}$ and Rozas's $R^{2}$, were significant for the whole dataset. Moreover, Fu's $F_{\mathrm{s}}$ and Rozas's $R^{2}$ were significant when Atlantic populations were pooled together, and for the Costa Brava when only Lineage I was considered. The Tajima's $D$ test was not significant for the Atlantic basin and Lineage I in Costa Brava, but Ramos-Onsins and Rozas (2002) suggested that the $F_{\mathrm{s}}$ and $R^{2}$ tests are more powerful than Tajima's $D$ in detecting population changes. Negative values of Tajima's $D$ and Fu's $F_{\text {s }}$ tests have been interpreted as signatures of population expansion (Table 5).
We estimated an approximate time of expansion $(t)$ for the Atlantic geographical region and Lineage I from the Mediterranean basin. From our estimations, the expansion might have taken place approximately between 81,400 and 57,000 generations ago in the Atlantic side and between 87,800 and 61,400 generations ago in the Mediterranean (mutation rates of 3.5 and $5 \%$ per my, respectively). Lacking information on $M$. glacialis sexual maturation, we inferred these data from other sea stars in which full maturity is reached in a period of 2-3 years (Yamaguchi and Lucas 1984; Bos et al. 2008). Using this information as an estimate of the generation time, then the expansion events occurred around 162,800-114,000 years ago in the Atlantic Ocean and 175,600-122,800 years ago into the Mediterranean basin for Lineage I. 
Table 5 Neutrality tests for each population of Marthasterias glacialis and for Atlantic and Mediterranean basin including and excluding Lineage II

\begin{tabular}{lcll}
\hline & Tajima's D & Fu's Fs & Rozas' ${ }^{2}$ \\
\hline Atlantic basin & -1.66772 & $-51.747^{* *}$ & $0.0376^{*}$ \\
UK & 0.03324 & -1.04921 & 0.116 \\
PV & -0.95613 & $-5.2132^{* *}$ & 0.084 \\
ST & -1.08945 & -1.62230 & 0.090 \\
G & -0.69720 & $-6.09772^{*}$ & 0.091 \\
CAS & -0.51871 & -1.29340 & 0.100 \\
SV & -1.44166 & $-4.72095^{*}$ & $0.0711^{* *}$ \\
SA & $-1.56076^{*}$ & -1.10765 & 0.102 \\
AZ & -0.35691 & -1.9480 & 0.1298 \\
Mediterranean basin & & & \\
Lineage I \& II & -0.55056 & -3.73360 & 0.0936 \\
Lineage I & -1.4101 & $-6.633^{* *}$ & $0.1245^{* *}$ \\
Total & $-1.85632 *$ & $-62.928^{* *}$ & $0.0319^{* *}$ \\
\hline
\end{tabular}

* Signification at $P<0.05$ and ** highly significant when $P<0.01$

\section{Discussion}

Lineage divergence

One of the most distinctive findings from our results was the existence of two highly divergent lineages of Marthasterias glacialis within the Mediterranean basin. Estimation of lineage split goes back to 830,000-580,000 years ago $( \pm 120,000)$ when both Mediterranean and Atlantic basins underwent important climatic and sea level fluctuations due to the Pleistocene glaciations. Glacial periods were associated with successive sea level drops (up to $120 \mathrm{~m}$ lower than currently), which dramatically affected the circulation between Atlantic and Mediterranean water masses and the coastal marine fauna (Patarnello et al. 2007; Maggs et al. 2008). Marine currents in the Gibraltar Strait likely became restricted limiting gene flow between basins, which might have promoted local adaptation and lineage divergence in M. glacialis at both sides of the Strait. Reestablishment of marine currents during interglacial periods might have allowed secondary contacts between populations from both basins with a recolonization of the Mediterranean by the Atlantic lineage. Contemporary water circulation between basins along the Gibraltar Strait, dominated by a strong surface inflow from the Atlantic into the Mediterranean as far as the Alboran Sea, may assist in maintaining a pattern of unidirectional gene flow from the Atlantic to the Mediterranean. The hypothesis of allopatric divergence in $M$. glacialis is reinforced by a strong genetic divergence lacking intermediate haplotypes between lineages and consistent with data obtained by Baric and Sturmbauer (1999) for the brittlestar Ophiothrix fragilis. These authors found two mitochondrial lineages in the species, one of them being endemic to the Mediterranean and the other with AtlantoMediterranean distribution, caused by recent recolonization from the Atlantic to the Mediterranean basin. Allopatric divergence by vicariance events has been invoked as one of the most likely models of genetic differentiation and speciation process promoting genetic discontinuities (Palumbi 1994; Cunningham and Collins 1998). A number of studies on Echinodermata have already addressed this particular matter (see examples in Lessios et al. 2001; Wares 2001; Waters et al. 2004; Addison and Hart 2005).

Whether lineages of $M$. glacialis belong to two different taxonomic entities is a problematic question lacking biological, reproductive and ecological information from both lineages. Applying molecular markers has demonstrated prevalence of cryptic and sibling species in marine environments otherwise undetectable from classical techniques of morphological analysis (Palumbi 1994; Knowlton 2000; Feral 2002), but the criteria to distinguish species from molecular data are not standing yet (Avise 1994; Lee 2004). The degree of divergence to define taxonomic units is variable between animal groups, and the comparison with closely related taxa is necessary before reaching consistent conclusions (Hebert et al. 2003). Within the Echinodermata, there is a wide range of intraspecific and interspecific variability for the COI; for instance, a $7 \%$ of divergence separated cryptic species of Holothuria nobilis, which was also consistent with colour patterns (Uthicke and Benzie 2003). Deep divergence into lineages of the sea star Coscinasterias muricata between North and South Australian populations (7.3\% for COI) and the correlation between mitochondrial and nuclear markers demonstrated that reproductive isolation had evolved for both forms of the species (Waters and Roy 2003). Within the Asteroidea, genetic distances for COI ranged from 2.5 to $24 \%$ among nominal species of Asterinidae (Waters et al. 2004; Hart et al. 1997). However, large databases have recently showed that average of conspecific divergence in Echinodermata is around 2\% for COI (Ward et al. 2008; Uthicke et al. 2010), with the highest levels of intraspecific variability reaching maximum values of $2.23 \%$ for some of the species studied. The $2.9 \%$ of divergence obtained between the sympatrically distributed lineages of $M$. glacialis is higher than those intraspecific values observed in other Echinodermata and might reflect the existence of two cryptic species. The extent of reproductive isolation for both lineages should be further tested by nuclear markers.

Demographic history and population genetics of lineage I

Sequences of COI from Marthasterias glacialis provided insight into the historical demography of the species. This 
mitochondrial marker was characterized by a relatively low nucleotide diversity and high haplotype diversity, comparable to those of other echinoderms (McCartney et al. 2000; Uthicke and Benzie 2003; Addison and Hart 2005) and probably due to a recent expansion of the species along the Atlantic and Mediterranean Sea. Several points from our data supported the hypothesis of historical expansion; (1) a star-shaped network with a few high-frequency central haplotypes connected with many low-frequency haplotypes (Templeton et al. 1995), (2) significant negative Tajimas' $D$ and Fu $F s$ tests and (3) a unimodal mismatch distribution, for Atlantic pool and Mediterranean lineage I, fitting within the expected expansion model, which has frequently been attributed to a population expansion after periods of small effective population size (Rogers and Harpending 1992). A bimodal distribution detected for the Mediterranean area emerges from grouping together two genetic pools holding different demographic history. Unimodal distributions in other marine invertebrates have been related to episodes of sea level oscillations during the Pleistocene and prior to the last glacial maximum 18,000 years ago (Zulliger et al. 2009; Couceiro et al. 2007). According to our results, a rapid population expansion after a glacial period would explain the present diversity of the species (Avise et al. 1984). From a more detailed analysis of the mismatch distribution test at both basins, we detected a double peak pattern that probably corresponds to two successive population increases in size. Based on a mutation rate of 5\%-My and the frequencies of pairwise differences, we estimate that the first and second expansions happened in the Mediterranean sea, around 127,000 and 48,000 years ago, respectively, and 96,000 and 31,000 years ago in the Atlantic basin, which may correspond to two interglacial periods before the last Pleistocene glaciation. However, our estimations of expansion times may be biased concerning the Mediterranean due to the reduced effective population size and the different numbers of generations per year reported for Atlantic and Mediterranean populations.

Marthasterias glacialis was also characterized by an absence of differentiation along the Atlantic Iberian Peninsula and the Mediterranean coast within Lineage I, and only Plymouth and Azores were significantly different from other populations. The absence of population subdivision at both sides of the Gibraltar Strait strongly contrasts with population differentiation patterns across the AtlantoMediterranean transition described for a number of marine invertebrate species (see Borsa et al. 1997; Patarnello et al. 2007). Although discrepancies between population genetic patterns for high dispersal echinoderms between Atlantic and Mediterranean sea suggest that similar biological features do not necessarily imply similar population structure (Calderon et al. 2008; Muths et al. 2009; Zulliger et al.
2009), a number of the marine invertebrate species analysed demonstrated either a common pattern of "genetic divergence" at both sides of this Strait or isolation by distance (see e.g. Quesada et al. 1995; Zane et al. 2000; Pérez-Losada et al. 2002). Hence, biogeographic barriers may be differentially permeable even for species with similar dispersal abilities (Addison and Hart 2005), and genetic patterns likely result from the stochastic nature of larval dispersal, colonization events and historical demography. Panmixia of M. glacialis along the Atlantic Iberian Peninsula and Mediterranean basin may be explained by either (A) a contemporaneous unidirectional gene flow from the Atlantic to the Mediterranean basin or (B) a past intense gene flow implying that the current gene frequencies have not already returned to equilibrium for mitochondrial DNA (Avise 1994; Palumbi 1994; Benzie 1999). Recolonization of the Mediterranean by members of the Atlantic lineage might have resulted in a genetic homogenization over the entire distribution range of the species, which could explain the lack of genetic subdivision. Since patterns of haplotype frequencies and distribution may be difficult to interpret in terms of contemporary gene flow and given that hypotheses A and B are not mutually exclusive, any of them can be discarded. Future analyses including markers evolving at higher rate to infer recent processes will be necessary in order to estimate the present levels of connectivity in this species.

Despite the apparent panmixia of $M$. glacialis along the Iberian Peninsula, the populations of UK (Plymouth) and Azores were different from all the other populations. Such a distinctive genetic structure of both populations may be explained by the geographic distribution of the species. This sea star is widely distributed along the northeast Atlantic and Mediterranean Sea but absent in the English Channel, Plymouth being the limit of its distribution within the Channel (Savy 1987; Ellis and Rogers 2000). On the other hand, the Azores islands are located at the western limit of distribution of the species. Although the UK population had haplotypes represented within all the main clades, a closer approximation highlights the lowest percentage of private haplotypes and the lack of one of the main ancestral haplotypes (H12). Populations in the distribution limits may be submitted to periodical extinction events. Survival of the UK population might happen by sporadic recruitment events from northern sources whose population structure is unknown. This would explain the absence of one of the most widespread haplotypes, the lowest occurrence of private haplotypes and the fact that the Plymouth population is the only one with no evidence of demographic expansion, positive values of Tajima's $D$ and the highest ones for Fu's $F s$ and $R^{2}$ tests. On the other hand, the remote population of Azores, with some private haplotypes, seems to be relatively isolated with certain 
recruitment from southern Portugal (Cascais and São Vicente).

\section{Conclusions}

From the data obtained in this study, we interpret that sea level fluctuations during Pleistocene glaciations promoted allopatric differentiation of lineages and speciation in M. glacialis and played an important role in shaping the genetic diversity of this species. In addition to a recolonization of the Mediterranean from the Atlantic lineage, demographic expansions might have erased previous population genetic structure. Therefore, the genetic patterns may be far from the equilibrium, and they may not necessary reflect the contemporary genetic exchange. The distinct structure of Plymouth population and the lack of correlation between genetic differentiation and geographical distance suggest that historical factors, such as haphazard arrival of larvae and local extinctions, rather than contemporary gene flow are responsible for this peculiar pattern. On the other hand, the remoteness of Azores islands might explain the structure of this population.

Acknowledgments Samples of Marthasterias glacialis from south Portugal were collected during the oceanographic expedition "LUSOEXPEDIÇÃO Olympus 2008" to the "Gorringe Seamounts". This research was supported by a postdoctoral fellowship from the FCT of Portugal (Ref. SFRH/BPD/41055/2007) funded by the Pluriannual Program (FCT, UI\&D 331/94, partially FEDER funded) and the project CMT2007-66635 (MARMOL) from the Spanish Ministry of Science. We strongly thank Xavier Mina for collecting samples from Mutriku, Pablo López for samples from Santander, Gustavo Martins and Joana Micael for samples from Azores, Fernando Roneberg for his help and support during the collection work and Sonia Chenu for her technical assistance in the laboratory.

\section{Appendix}

See Table 6.

Table 6 Haplotype frequencies of Marthasterias glacialis per population. Numbers in bold are private haplotypes

\begin{tabular}{|c|c|c|c|c|c|c|c|c|c|c|}
\hline & UK & PV & ST & $\mathrm{G}$ & CAS & SV & SA & $\mathrm{CB}$ & SP & $\mathrm{AZ}$ \\
\hline H_1 & 0 & 0 & 0 & 0 & 0 & 0.0455 & 0 & 0 & 0 & 0.0767 \\
\hline H_2 & 0 & 0 & 0 & 0 & 0 & 0.0455 & 0 & 0 & 0 & 0 \\
\hline H_3 & 0 & 0 & 0 & 0 & 0 & 0.0455 & 0 & 0 & 0 & 0 \\
\hline H_4 & 0 & 0 & 0 & 0 & 0 & 0.0455 & 0 & 0 & 0 & 0 \\
\hline H_5 & 0 & 0 & 0 & 0 & 0 & 0.0455 & 0 & 0 & 0 & 0.3076 \\
\hline H_6 & 0.0174 & 0.333 & 0.35 & 0.250 & 0.290 & 0.273 & 0.316 & 0.226 & 0.333 & 0 \\
\hline H_7 & 0 & 0 & 0 & 0 & 0 & 0.0455 & 0 & 0 & 0 & 0 \\
\hline H_8 & 0 & 0 & 0 & 0 & 0 & 0.0455 & 0 & 0 & 0 & 0 \\
\hline H_9 & 0.0357 & 0 & 0.1 & 0 & 0 & 0.455 & 0 & 0.0323 & 0 & 0 \\
\hline H_10 & 0 & 0 & 0 & 0 & 0 & 0.0455 & 0 & 0 & 0 & 0 \\
\hline H_11 & 0.143 & 0.1 & 0.5 & 0.0357 & 0 & 0.136 & 0 & 0.129 & 0 & 0 \\
\hline H_12 & 0 & 0.133 & 0.2 & 0.0357 & 0.161 & 0.136 & 0.421 & 0.0323 & 0 & 0.0769 \\
\hline H_13 & 0 & 0 & 0 & 0 & 0 & 0.0455 & 0 & 0 & 0 & 0 \\
\hline H_14 & 0 & 0 & 0 & 0 & 0 & 0 & 0.0526 & 0 & 0 & 0 \\
\hline H_15 & 0.0357 & 0.0333 & 0.05 & 0.0714 & 0 & 0 & 0.0526 & 0.0323 & 0.666 & 0 \\
\hline H_16 & 0 & 0 & 0 & 0 & 0 & 0 & 0.0526 & 0 & 0 & 0 \\
\hline H_17 & 0 & 0 & 0 & 0 & 0 & 0 & 0.0526 & 0 & 0 & 0 \\
\hline H_18 & 0 & 0 & 0 & 0 & 0 & 0 & 0.0526 & 0 & 0 & 0 \\
\hline H_19 & 0 & $\mathbf{0 . 0 3 3 3}$ & 0 & 0 & 0 & 0 & 0 & 0 & 0 & 0 \\
\hline H_20 & 0 & $\mathbf{0 . 0 3 3 3}$ & 0 & 0 & 0 & 0 & 0 & 0 & 0 & 0 \\
\hline H_21 & 0.0357 & 0.0333 & 0 & 0.0357 & 0.0645 & 0 & 0 & 0 & 0 & 0 \\
\hline H_22 & 0 & $\mathbf{0 . 0 3 3 3}$ & 0 & 0 & 0 & 0 & 0 & 0 & 0 & 0 \\
\hline H_23 & 0 & $\mathbf{0 . 0 3 3 3}$ & 0 & 0 & 0 & 0 & 0 & 0 & 0 & 0 \\
\hline H_24 & 0.0714 & 0.1 & 0 & 0 & 0.0323 & 0 & 0 & 0.0323 & 0 & 0 \\
\hline H_25 & 0 & 0.0333 & 0 & 0 & 0 & 0 & 0 & 0 & 0 & 0 \\
\hline H_26 & 0.0714 & 0.0333 & 0 & 0.143 & 0.161 & 0 & 0 & 0 & 0 & 0 \\
\hline H_27 & 0 & 0.0333 & 0 & 0 & 0 & 0 & 0 & 0 & 0 & 0 \\
\hline H_28 & 0 & $\mathbf{0 . 0 3 3 3}$ & 0 & 0 & 0 & 0 & 0 & 0 & 0 & 0 \\
\hline
\end{tabular}


Table 6 continued

\begin{tabular}{|c|c|c|c|c|c|c|c|c|c|c|}
\hline & UK & PV & ST & G & CAS & SV & SA & $\mathrm{CB}$ & SP & $\mathrm{AZ}$ \\
\hline H_29 & 0 & 0 & 0 & 0.0357 & 0 & 0 & 0 & 0 & 0 & 0 \\
\hline H_30 & 0 & 0 & 0 & 0.0357 & 0 & 0 & 0 & 0 & 0 & 0 \\
\hline H_31 & 0 & 0 & 0 & 0.0714 & 0 & 0 & 0 & 0 & 0 & 0 \\
\hline H_32 & 0 & 0 & 0 & 0.0357 & 0 & 0 & 0 & 0 & 0 & 0 \\
\hline H_33 & 0 & 0 & 0 & 0.0357 & 0 & 0 & 0 & 0 & 0 & 0 \\
\hline H_34 & 0 & 0 & 0 & 0.0357 & 0 & 0 & 0 & 0 & 0 & 0 \\
\hline H_35 & 0 & 0 & 0 & 0.0357 & 0 & 0 & 0 & 0 & 0 & 0 \\
\hline H_36 & 0 & 0 & 0 & 0.0357 & 0 & 0 & 0 & 0 & 0 & 0 \\
\hline H_37 & 0 & 0 & 0 & 0.0357 & 0 & 0 & 0 & 0.0323 & 0 & 0 \\
\hline H_38 & 0 & 0 & 0 & 0.0357 & 0 & 0 & 0 & 0 & 0 & 0 \\
\hline H_39 & 0 & 0 & 0 & 0.0357 & 0 & 0 & 0 & 0 & 0 & 0 \\
\hline H_40 & 0.0357 & 0 & 0 & 0 & 0 & 0 & 0 & 0 & 0 & 0 \\
\hline H_41 & 0.0357 & 0 & 0 & 0 & 0 & 0 & 0 & 0 & 0 & 0 \\
\hline H_42 & 0.0714 & 0 & 0 & 0 & 0 & 0 & 0 & 0 & 0 & 0 \\
\hline H_43 & 0.0357 & 0 & 0 & 0 & 0 & 0 & 0 & 0 & 0 & 0 \\
\hline H_44 & 0.0357 & 0 & 0 & 0 & 0 & 0 & 0 & 0 & 0 & 0 \\
\hline H_45 & 0 & 0 & 0 & 0 & 0 & 0 & 0 & 0.0323 & 0 & 0 \\
\hline H_46 & 0 & 0 & 0 & 0 & 0 & 0 & 0 & 0.0129 & 0 & 0 \\
\hline H_47 & 0 & 0 & 0 & 0 & 0 & 0 & 0 & 0.0323 & 0 & 0 \\
\hline H_48 & 0 & 0 & 0 & 0 & 0 & 0 & 0 & 0.0323 & 0 & 0 \\
\hline H_49 & 0 & 0 & 0 & 0 & 0 & 0 & 0 & 0.0323 & 0 & 0 \\
\hline H_50 & 0 & 0 & 0 & 0 & 0 & 0 & 0 & 0.0323 & 0 & 0 \\
\hline H_51 & 0 & 0 & 0 & 0 & 0 & 0 & 0 & 0.0323 & 0 & 0 \\
\hline H_52 & 0 & 0 & 0 & 0 & 0 & 0 & 0 & 0.0323 & 0 & 0 \\
\hline H_53 & 0 & 0 & 0 & 0 & 0 & 0 & 0 & 0.0323 & 0 & 0 \\
\hline H_54 & 0 & 0 & 0 & 0 & 0 & 0 & 0 & 0.0323 & 0 & 0 \\
\hline H_55 & 0 & 0 & 0 & 0 & 0 & 0 & 0 & 0.0323 & 0 & 0 \\
\hline H_56 & 0 & 0 & 0 & 0 & 0 & 0 & 0 & 0.0323 & 0 & 0 \\
\hline H_57 & 0 & 0 & 0 & 0 & 0 & 0 & 0 & 0 & 0 & 0.0769 \\
\hline H_58 & 0 & 0 & 0 & 0 & 0.0645 & 0 & 0 & 0 & 0 & 0.0769 \\
\hline H_59 & 0 & 0 & 0 & 0 & 0.0323 & 0 & 0 & 0 & 0 & 0 \\
\hline H_60 & 0 & 0 & 0 & 0 & 0.0645 & 0 & 0 & 0 & 0 & 0 \\
\hline H_61 & 0 & 0 & 0 & 0 & 0.0323 & 0 & 0 & 0 & 0 & 0 \\
\hline H_62 & 0 & 0 & 0 & 0 & 0.0323 & 0 & 0 & 0 & 0 & 0 \\
\hline H_63 & 0 & 0 & 0 & 0 & 0.0323 & 0 & 0 & 0 & 0 & 0 \\
\hline H_64 & 0 & 0 & 0 & 0 & 0.0323 & 0 & 0 & 0 & 0 & 0 \\
\hline H_65 & 0 & 0 & 0.05 & 0 & 0 & 0 & 0 & 0 & 0 & 0 \\
\hline H_66 & 0 & 0 & 0.05 & 0 & 0 & 0 & 0 & 0 & 0 & 0 \\
\hline H_67 & 0 & 0 & 0.05 & 0 & 0 & 0 & 0 & 0 & 0 & 0 \\
\hline H_68 & 0 & 0 & 0.05 & 0 & 0 & 0 & 0 & 0 & 0 & 0 \\
\hline H_69 & 0 & 0 & 0.05 & 0 & 0 & 0 & 0 & 0 & 0 & 0 \\
\hline H_70 & 0 & 0 & 0 & 0 & 0 & 0 & 0 & 0 & 0 & 0.0769 \\
\hline H_71 & 0 & 0 & 0 & 0 & 0 & 0 & 0 & 0 & 0 & 0.0769 \\
\hline H_72 & 0 & 0 & 0 & 0 & 0 & 0 & 0 & 0 & 0 & 0.0769 \\
\hline H_73 & 0 & 0 & 0 & 0 & 0 & 0 & 0 & 0 & 0 & 0.1538 \\
\hline
\end{tabular}




\section{References}

Addison JA, Hart MW (2004) Analysis of population genetic structure of the green sea urchin (Strongylocentrotus droebachiensis) using microsatellites. Mar Biol 144:243-251

Addison JA, Hart MW (2005) Colonization, dispersal, and hybridization influence phylogeography of North Atlantic sea urchins (Strongylocentrotus droebachiensis). Evolution 59:532-543

Avise JC (1994) Molecular markers, natural history and evolutionl. Chapman and Hall, London

Avise JC (2000) Phylogeography: the history and formation of species, Vol. Harvard University Press, Cambridge

Avise JC, Neigel JE, Arnold J (1984) Demographic influences on mitochondrial DNA lineage survivorship in animal populations. J Mol Evol 20:99-105

Bandelt HJ, Forster P, Rohl A (1999) Median-joining networks for inferring intraspecific phylogenies. Mol Biol Evol 16:37-48

Bargelloni L, Alarcon JA, Alvarez MC, Penzo E, Magoulas A, Reis C, Patarnello T (2003) Discord in the family Sparidae (Teleostei): divergent phylogeographical patterns across the AtlanticMediterranean divide. J Evol Biol 16:1149-1158

Baric S, Sturmbauer C (1999) Ecological parallelism and cryptic species in the genus Ophiothrix derived from mitochondrial DNA sequences. Mol Phylogenet Evol 11:157-162

Barker MF, Nichols D (1983) Reproduction, recruitment and juvenile ecology of the starfish, Asterias-rubens and Marthasterias glacialis. J Mar Biol Ass UK 63:745-765

Barton NH, Hewitt GM (1985) Analysis of hybrid zones. Annu Rev Ecol Syst 16:113-148

Benzie JAH (1999) Major genetic differences between crown-ofthorns starfish (Acanthaster planci) populations in the Indian and Pacific Oceans. Evolution 53:1782-1795

Borsa P, Naciri M, Bahri L, Chikhi L, Garcia de León FJ, Kotoulas G, Bonhomme F (1997) Intraspecific zoogeography of the Mediterranean: population genetic analysis on sixteen atlanto-mediterranean species (fishes and invertebrates). Vie et Milieu 47:295-305

Bos AR, Gumanao GS, Alipoyo JCE, Cardona LT (2008) Population dynamics, reproduction and growth of the Indo-Pacific horned sea star, Protoreaster nodosus (Echinodermata; Asteroidea). Mar Biol 156:55-63

Calderon I, Giribet G, Turon X (2008) Two markers and one history: phylogeography of the edible common sea urchin Paracentrotus lividus in the Lusitanian region. Mar Biol 154:137-151

Cimmaruta R, Bondanelli P, Nascetti G (2005) Genetic structure and environmental heterogeneity in the European hake (Merluccius merluccius). Mol Ecol 14:2577-2591

Clarke KR, Warwick RM (2001) Change in marine communities: an approach to statistical analysis and interpretation, 2nd edn. PRIMER-E, Plymouth

Couceiro L, Barreiro R, Ruiz JM, Sotka EE (2007) Genetic isolation by distance among populations of the netted dog whelk Nassarius reticulatus (L.) along the European Atlantic coastline. J Hered 98:603-610

Cunningham CW, Collins TM (1998) Beyond area relationships: extinction and recolonization in molecular marine biogeography. In: Schierwater B, Streit B, Wagner G, DeSalle R (eds) Molecular ecology and evolution: approaches and applications. Birkhauser Verlag, Basel, pp 297-321

Dupanloup I, Schneider S, Excoffier L (2002) A simulated annealing approach to define the genetic structure of populations. Mol Ecol 11:2571-2581

Duran S, Palacin C, Becerro MA, Turon X, Giribet G (2004) Genetic diversity and population structure of the commercially harvested sea urchin Paracentrotus lividus (Echinodermata, Echinoidea). Mol Ecol 13:3317-3328

Ellis JR, Rogers SI (2000) The distribution, relative abundance and diversity of echinoderms in the eastern English Channel, Bristol Channel, and Irish Sea. J Mar Biol Ass UK 80:127-138

Excoffier L, Laval G, Schneider S (2005) Arlequin (version 3.0): an integrated software package for population genetics data analysis. Evol Bioinform Online 1:47-50

Feral JP (2002) How useful are the genetic markers in attempts to understand and manage marine biodiversity? J Exp Mar Biol Ecol 268:121-145

Folmer O, Black M, Hoeh W, Lutz R, Vrijenhoek R (1994) DNA primers for amplification of mitochondrial cytochrome c oxidase subunit I from diverse metazoan invertebrates. Mol Mar Biol Biotech 3:294-299

Frid CLJ (1992) Foraging behavior of the spiny starfish Marthasteria glacialis in Lough Ine, Co Cork. Mar Behav Physiol 19:227-239

Fu YX (1997) Statistical test of neutrality of mutations against population growth, hitchhiking and background selection. Genetics 147:915-925

Guidetti P (2004) Consumers of sea urchins, Paracentrotus lividus and Arbacia lixula, in shallow Mediterranean rocky reefs. Helgoland Mar Res 58:110-116

Harmelin J, Bouchon C, Duval C, Hong J (1980) Les échinodermes des substrats durs de l'ile de Port-Cros, Parc National. Elément pour un inventaire quantitatif. Trav Sci Parc Nation Port-Cros 6:25-38

Hart MW, Byrne M, Smith MJ (1997) Molecular phylogenetic analysis of life-history evolution in Asterinid starfish. Evolution 51:1848-1861

Hebert PDN, Ratnasingham S, de Waard JR (2003) Barcoding animal life: cytochrome c oxidase subunint 1 divergences among closely related species. Proc R Soc Lond 270:96-99

Hedgecock D, Barber PH, Edmands S (2007) Genetic approaches to measuring connectivity. Oceanography 20:70-79

Hellberg ME (1996) Dependence of gene flow on geographic distance in two solitary corals with different larval dispersal capabilities. Evolution 50:1167-1175

Huelsenbeck JP, Ronquist F (2001) MRBAYES: bayesian inference of phylogenetic trees. Bioinformatics 17:754-755

Hunter RL, Halanych KM (2008) Evaluating connectivity in the brooding brittle star Astrotoma agassizii across the Drake passage in the Southern Ocean. J Hered. doi:10.1093/ jhered/esm119

Knowlton N (2000) Molecular genetic analyses of species boundaries in the sea. Hydrobiologia 420:73-90

Launey S, Ledu C, Boudry P, Bonhomme F, Naciri-Graven Y (2002) Geographic structure in the European flat oyster (Ostrea edulis L.) as revealed by microsatellite polymorphism. J Hered 93:331338

Le Gac M, Feral JP, Poulin E, Veyret M, Chenuil A (2004) Identification of allopatric clades in the cosmopolitan ophiuroid species complex Amphipholis squamata (Echinodermata). The end of a paradox? Mar Ecol Prog Ser 278:171-178

Lee M (2004) The molecularisation of taxonomy. Invertebr Sys $18: 1-6$

Lessios HA, Kessing BD, Robertson DR, Paulay G (1999) Phylogeography of the pantropical sea urchin Eucidaris in relation to land barriers and ocean currents. Evolution 53:806-817

Lessios HA, Kessing BD, Pearse JS (2001) Population structure and speciation in tropical seas: global phylogeography of the sea urchin Diadema. Evolution 55:955-975

Lessios HA, Kane J, Robertson DR, Wallis G (2003) Phylogeography of the pantropical sea urchin Tripneustes: contrasting patterns of population structure between oceans. Evolution 57:2026-2036 
Maggs CA, Castilho R, Foltz D, Henzler C, Jolly MT, Kelly J, Olsen J, Perez KE, Stam W, Väinölä R, Viard F, Wares J (2008) Evaluating signatures of the glacial refugia for North Atlantic benthic marine taxa. Ecology 89:108-122

Mccartney M, Keller G, Lessios HA (2000) Dispersal barriers in tropical oceans and speciation in Atlantic and eastern Pacific sea urchins of the genus Echinometra. Mol Ecol 9:1391-1400

Mortensen T (1927) Echinoderms of the British Isles. VIII. Oxford University Press, Oxford, $\mathrm{p} 471$

Muths D, Jollivet D, Gentil F, Davoult D (2009) Large-scale genetic patchiness among NE Atlantic populations of the brittle star Ophiothrix fragilis. Aquat Biol 5:117-132

Nichols D, Barker MF (1984) Reproductive and nutritional periodicities in the starfish, Marthasterias glacialis, from Plymouth Sound. J Mar Biol Ass UK 64:461-470

Palumbi SR (1994) Genetic divergence, reproductive isolation, and marine speciation. Annu Rev Ecol Syst 25:547-572

Palumbi SR (1995) Using genetics as an indirect estimator of larval dispersal. In: McEdward L (ed) Ecology of marine invertebrate larvae. CRC Press, Boca Raton, pp 369-387

Patarnello T, Volckaert F, Castilho R (2007) Pillars of Hercules: is the Atlantic-Mediterranean transition a phylogeographical break? Mol Ecol 16:4426-4444

Pérez-Losada M, Guerra A, Carvalho GR, Sanjuan A, Shaw PW (2002) Extensive population subdivision of the cuttlefish Sepia officinalis (Mollusca: Cephalopoda) around the Iberian Peninsula indicated by microsatellite DNA variation. Heredity 89:417-424

Pérez-Portela R, Turon X (2008) Cryptic divergence and strong population structure in the colonial invertebrate Pycnoclavella communis (Ascidiacea) inferred from molecular data. Zoology 111:163-178

Posada D, Crandall KA (1998) MODELTEST: testing the model of DNA substitution. Bioinformatics 14:817-818

Quesada H, Beynon CM, Skibinski DOF (1995) A mitochondrialDNA discontinuity in the mussel Mytilus galloprovincialis (Lmk): pleistocene vicariance biogeography and secondary intergradation. Mol Biol Evol 12:521-524

Ramos-Onsins SE, Rozas J (2002) Statistical properties of new neutrality tests against population growth. Mol Biol Evol 19:2092-2100

Rios C, Sanz S, Saavedra C, Pena JB (2002) Allozyme variation in populations of scallops, Pecten jacobaeus (L.) and P maximus (L.) (Bivalvia : Pectinidae), across the Almeria-Oran front. J Exp Mar Biol Ecol 267:223-244

Rogers AR (1995) Genetic-evidence for a pleistocene population explosion. Evolution 49:608-615

Rogers AR, Harpending H (1992) Population-growth makes waves in the distribution of pairwise genetic-differences. Mol Biol Evol 9:552-569

Rousset F (1997) Genetic differentiation and estimation of gene flow from F-statistics under isolation by distance. Genetics 145:12191228

Rozas J, Rozas R (1999) DNAsp version 3.0: an integrated program for molecular population genetics and molecular evolution analyses. Bioinformatics 15:174-175

Rozas J, Sanchez-DelBarrio JC, Messeguer X, Rozas R (2003) DnaSP, DNA polymorphism analyses by the coalescent and other methods. Bioinformatics 19:2496-2497
Savy S (1987) Activity pattern of the sea-star, marthasterias-glacialis, in port-cros bay (France, Mediterranean Coast). PSZNI Mar Ecol 8:97-106

Solé-Cava AM, Thorpe JP (1991) High levels of genetic variation in natural populations of marine lower invertebrates. Biol J Linn Soc 44:65-80

Tajima F (1989) Statistical-method for testing the neutral mutation hypothesis by DNA polymorphism. Genetics 123:585-595

Tarjuelo I, Posada D, Crandall KA, Pascual M, Turon X (2001) Cryptic species of Clavelina (Ascidiacea) in two different habitats: harbours and rocky littoral zones in the northwestern Mediterranean. Mar Biol 139:455-462

Templeton AR, Sing CF (1993) A Cladistic-analysis of phenotypic associations with haplotypes inferred from restriction endonuclease mapping 4 . Nested analyses with cladogram uncertainty and recombination. Genetics 134:659-669

Templeton AR, Boerwinkle E, Sing CF (1987) A cladistic analysis of phenotypic associations with haplotypes inferred from restriction endonuclease mapping. I. Basic theory and an analysis of alcohol dehydrogenase activity in Drosophila. Genetics 117:343-351

Templeton AR, Routman E, Phillips CA (1995) Separating population structure from population history: a cladistic analysis of the geographical distribution of mitochondrial DNA haplotypes in the Tiger Salamander, Ambystoma tigrinum. Genetics 140:767782

Uthicke S, Benzie JAH (2003) Gene flow and population history in high dispersal marine invertebrates: mitochondrial DNA analysis of Holothuria nobilis (Echinodermata: Holothuroidea) populations from the Indo-Pacific. Mol Ecol 12:2635-2648

Uthicke S, Byrne M, Conand C (2010) Genetic Barcoding of commercial Bêche-de-mer species (Echinodermata: Holothuroidea). Mol Ecol Resour

Ward R, Holmes B, O'hara T (2008) DNA barcoding discriminates echinoderm species. Mol Ecol Resour 8:1202-1211

Wares JP (2001) Biogeography of Asterias: North Atlantic climate change and speciation. Biol Bull 201:95-103

Wares JP, Cunningham CW (2001) Phylogeography and historical ecology of the North Atlantic intertidal. Evolution 55:2455-2469

Waters JM, Roy MS (2003) Marine biogeography of southern Australia: phylogeographical structure in a temperate sea-star. J Biogeog 30:1787-1796

Waters JM, O'Loughlin PM, Roy MS (2004) Cladogenesis in a starfish species complex from southern Australia: evidence for vicariant speciation? Mol Phylogenet Evol 32:236-245

Yamaguchi M, Lucas JS (1984) Natural parthenogenesis, larval and juvenile development, and geographical distribution of the coral reef asteroid Ophidiaster granifer. Mar Biol 83:33-42

Zane L, Ostellari L, Maccatrozzo L, Bargelloni L, Cuzin-Roudy J, Buchholz F, Patarnello T (2000) Genetic differentiation in a pelagic crustacean (Meganyctiphanes norvegica: Euphausiacea) from the North East Atlantic and the Mediterranean Sea. Mar Biol 136:191-199

Zulliger D, Tanner S, Ruch M, Ribi G (2009) Genetic structure of the high dispersal Atlanto-Mediterreanean sea star Astropecten aranciacus revealed by mitochondrial DNA sequences and microsatellite loci. Mar Biol 156:597-610 